\title{
Radial tree-growth modelling with fuzzy regression
}

\author{
J J. Boreux, C. Gadbin-Henry, J. Guiot, and L. Tessier
}

\begin{abstract}
A so-called fuzzy linear regression is used in dendroecology to model empirically tree growth as a function of a bioclimatic index representing the water stress, i.e., the ratio of actual evapotranspiration to potential evapotranspiration. The response function predicts tree growth as (fuzzy) intervals, narrow in the domain where the bioclimatic index is most limiting and becoming progressively larger elsewhere. The method is tested with a population of Pinus pinea L. from the Provence region in France. It is shown that fuzzy linear regression gives results comparable with those obtained using a linear response function. The interval of credibility given by the fuzzy regression suggests that more precise expected growth is obtained for high water stress, which is typical of Mediterranean climate. Fuzzy linear regression can be also a method to test different hypotheses on several potential predictors when any further experimental approach is quite impossible as it is for trees in their natural environment. To sum up, fuzzy regression could be a first step before the construction of a kind of growth simulator adapted to different environments of a given species. In environmental sciences, the fuzzy response function thus appears to be an approach between the mechanistic and the statistical descriptive approaches.
\end{abstract}

Résumé : Une régression dite linéaire floue est utilisée en dendroécologie pour modéliser empiriquement la croissance des arbres en fonction d'un indice bioclimatique représentant le stress hydrique, c'est-à-dire, le ratio de l'évapotranspiration réelle par rapport à l'évapotranspiration potentielle. La fonction prédit la croissance des arbres par intervalles (flous) qui sont étroits dans la région où l'indice bioclimatique est le plus limitatif et s'élargissent progressivement dans les autres régions. La méthode est testée avec une population de Pinus pinea L. de la région provençale de France. Il est démontré que la régression linéaire floue donne des résultats comparables à ceux obtenus avec une fonction à réponse linéaire. L'intervalle de crédibilité donné par la régression floue suggère une croissance plus precise attendue lors d'un stress hydrique élevé, typique du climat méditerranéen. La régression linéaire floue peut aussi servir à tester différentes hypothèses au sujet de prédicteurs potentiels lorsque toute approche expérimentale additionnelle est impossible, comme dans le cas des arbres dans leur environnement naturel. En conclusion, la régression floue pourrait constituer une première étape avant la construction d'une sorte de « simulateur de croissance » adapté aux différents milieux occupés par une espèce donnée. En sciences environnementales, la fonction de réponse floue semble donc être une approche qui se situe entre l'approche déterministe et l'approche des statistiques descriptives.

\section{Introduction}

Empirical statistical models (Fritts 1976) usually describe the response of tree growth to climate. Not all climate factors are important to a tree at any given moment. Only those that limit some process can affect growth (Fritts 1982). The principle of limiting factors states that each process is governed by one factor at a time, namely, the factor that is the most stressing at that time. However, as we want to calculate response functions valid for the whole live tree, it is neces-

Received December 22, 1997. Accepted May 17, 1998.

J.J. Boreux. Fondation universitaire luxembourgeoise, avenue de Longwy, 185, 6700 Arlon, Belgique. e-mail:

boreux@ful.ac.be

C. Gadbin-Henry, J. Guiot, ${ }^{1}$ and L. Tessier. Institut méditerranéen d'écologie et paléoécologie, Centre national de la recherche scientifique, Faculté de St-Jérôme, case 451, 13397 Marseille Cédex 20, France. e-mail:

claude.gadbin@1bhp.u-3mrs.fr; joel.guiot@1bhp.u-3mrs.fr, and lucien.tessier@lbhp.u-3mrs.fr

${ }^{1}$ Author to whom all correspondence should be addressed. sary to take into account a large number of possible limiting factors and thus to use multivariate statistics.

Since the pioneer paper of Fritts et al. (1971), monthly mean temperature and monthly precipitation over a period from 12 to 16 months before the end of the growth, i.e., August or September depending on the species and (or) the climate, are used as growth predictors. As such a large number of predictors is not without statistical problems (correlation of the predictors, reduced number of degrees of freedom, etc.); the set is reduced to independent variables by using principal component analysis (Fritts et al. 1971; Fritts 1976; Guiot et al. 1982a). The effects of using an excessively large number of predictors have been well established by Monte Carlo methods (Cropper 1982) or bootstrap ones (Guiot 1989).

Regrouping individual months into biological seasons according to some a priori knowledge of the tree ecology or on the basis of monthly response functions has also been tested to reduce the number of parameters in the models (Guiot et al. 1982b). More bioclimatic parameters, such as evapotranspiration, have also been introduced (Badeau et al. 1995; Bert 1992; Gadbin-Henry 1994 ; Lebourgeois 1995). Mechanistic models (Shashkin and Fritts 1995) are much more difficult to implement. In particular, the need for daily values as 
input into such bioclimatic or mechanistic models is difficult to satisfy most of the time.

Mechanistic models should be the favoured approach in the future, as they are the only ones to completely take into account the biology of the problem, thus insuring a greater robustness of the predictions. Here we do not propose such a model, but we stay at a more empirical level, which is the easiest approach when large sets of data, as available in dendroecology, must be analysed. Meanwhile, by trying to incorporate maximum a priori information into the model, we think that more useful predictive models can be elaborated. Bayesian or fuzzy logic methods are able to satisfy these requirements, either by estimating the model parameters from an a priori distribution (Bayesian approach) or by chosing a reference point where the knowledge is maximum and (or) by defining the shape of the fuzzy numbers according some biological considerations.

We test a so-called fuzzy linear regression on selected bioclimatic variables that take into account the uncertainties inevitable in most of the data. We also show that this approach is able to take into account the particular profile of the climatic effect on tree growth. The trees react to climate according to the limiting factor principle, which means that high values of the climatic factor do not have the same proportional effect as low values. It also means that this limiting factor can change during yearly tree growth and from one year to the next.

The method is illustrated by a population of Pinus pinea $\mathrm{L}$. from the Provence region in France.

\section{Methods}

\section{Field site}

A population of Pinus pinea L. has been retained for this study, because it grows in an healthy and large stand with an active regeneration, so it is able to reflect the average ecological conditions for this species. The sensitivity to climatic variations (called "mean sensitivity" by Douglass (1936) and denoted $S$ ) has a high level for a Mediterranean species $(S=0.26)$.

The site is located at an altitude of $105 \mathrm{~m}$, on an almost flat area near the small town of Vidauban, in the so-called Bois de Rouquan locality $\left(43^{\circ} 22 \mathrm{~N}, 6^{\circ} 27^{\prime} \mathrm{E}\right)$. The substratum is a sandstone outcrop of the Permian depression along the crystalline massif of the Maures. In such edaphic conditions, the main limiting climatic factor is humidity; this was demonstrated previously by comparing the radial growth of Pinus pinea $\mathrm{L}$. with both precipitation and bioclimatic coefficients such as real or potential evapotranspiration (Gadbin-Henry 1994).

Mediterranean-type climate prevails in the studied region characterized by a cold winter and a warm and dry summer. The aridity coefficient of Emberger (1930) at the nearest meteorological station classifies the site in the subhumid zone, with a total annual precipitation of $889 \mathrm{~mm}$, a mean annual temperature of $14.6^{\circ} \mathrm{C}$, a mean minimum value of $1.7^{\circ} \mathrm{C}$ for the coldest month, and a mean maximum value of $30.9^{\circ} \mathrm{C}$ for the warmest month.

The dominant trees were retained, because they were less affected by competition processes and thus were the best climate recorders (Schweingruber et al. 1990). Within this population, 14 dominant trees were selected to obtain the longest possible treering series, undisturbed by any accidental event. The raw data were provided by cores obtained with the Pressler borer (three samples per tree at $60^{\circ}$ intervals around the trunk). Tree-ring width, reflecting tree growth, were directly measured on planed cores with a tree-ring measuring system including integral recording. Compari- son of ring-width chronologies revealed a mean correlation of 0.95 . The whole population is represented by the mean chronology, including the 42 elementary chronologies.

Meteorological data for the period 1950-1985 (monthly precipitation and temperature) were provided by the nearest meteorological station having similar geographical and climatological characteristics (Fréjus; $43^{\circ} 26^{\prime} \mathrm{N}, 6^{\circ} 45^{\prime} \mathrm{E}$, altitude $50 \mathrm{~m}$ ).

\section{Bioclimatic variables}

We use three bioclimatic variables representing the water stress, winter frost, and thermal energy available in the growing season. These variables are derived from three monthly parameters easily available at a reasonable distance $(40 \mathrm{~km})$ from the tree-ring site analysed, i.e., the 12 monthly mean temperatures $\left({ }^{\circ} \mathrm{C}\right)$, monthly precipitation amount $(\mathrm{mm})$, and the monthly sunshine. Using the simple equations described in Harrison et al. (1993) and Prentice et al. (1993), these basic variables are transformed, for each year, into (i) the mean temperature of the coldest month $\left(T_{\mathrm{c}}\right.$ in $\left.{ }^{\circ} \mathrm{C}\right)$; $(\mathrm{ii})$ the growing degree-days above $5^{\circ} \mathrm{C}\left(\mathrm{GDD}_{5}\right.$ in degree-days); and (iii) the ratio of actual evapotranspiration to potential evapotranspiration $(\alpha$ in $\%)$.

As often, daily temperatures are not available for local meteorological stations, we have devised a method to roughly calculate them from monthly values by cubic-spline interpolation. $\mathrm{GDD}_{5}$ is obtained from these quasi-daily values by summing the part above $5^{\circ} \mathrm{C}$.

For the actual evapotranspiration, a simple water-balance model is used (Harrison et al. 1993). The actual evapotranspiration (AET) is taken to be the lesser of a supply function proportional to soil moisture (Federer 1982) and a demand function set equal to the potential evapotranspiration (PET). PET is empirically defined as a function of the net radiation and temperature (Jarvis and Macnaughton 1986). Net radiation is obtained as a semi-empirical function of insolation, sunshine proportion, and temperature and varies sinusoidally during the day, allowing daily actual and potential evapotranspiration to be obtained by integration (Prentice et al. 1992, 1993). Sunshine is indexed as a proportion of the maximum possible sunshine hours for the latitude and month under consideration. In addition to the three monthly climatic variables, latitude of the site and orbital parameters (eccentricity, obliquity, and phase angle indicating the timing of the perihelion relative to the equinoxes) are used as input variables. This method of calculating $\alpha$ is rather rough, but various tests (Gadbin-Henry 1994) have shown that this approximated parameter correlates well with the studied tree-growth series.

The model requires daily precipitation values, which are obtained by dividing the monthly precipitation by the number of days in the month. The soil moisture, $\Omega$, is obtained from January 1 to December 31 by integrating daily values calculated by adding the difference between daily precipitation and daily PET within a range $\left[0, \Omega_{\max }\right] . \Omega_{\max }$ is the soil water-holding capacity above which the water runs off. As no data are available for the year prior to the study, we start with a value of $\Omega$ equal to $\Omega_{\max }$, and for the following years, we start with the last value calculated for the previous year.

\section{Response function using a bootstrap multiple regression}

In dendroecology, it is usual to calculate the effect of climate on tree growth by a multiple regression, called a response function. This model often includes 24 predictors and sometimes more (Fritts 1976). It can be written as follows:

[1] $\quad Y_{i}=\beta_{0}+\sum_{j=1}^{m} \beta_{j} X_{i j}+\varepsilon_{i}$

where $Y_{i}$ is the value of the response in the $i$ th observation; $\beta_{0}$ and $\beta_{j}(j=1,2, \ldots, m)$ are the model parameters; $X_{i j}(j=1,2, \ldots, m)$ are 
Fig. 1. Standardized partial regression coefficients with the $90 \%$ confidence interval between tree growth at Vidauban and three bioclimatic variables. A vertical line completely above the horizontal axis means a significant positive effect of the corresponding bioclimatic parameter on the tree growth, and a line below shows a significant negative effect.

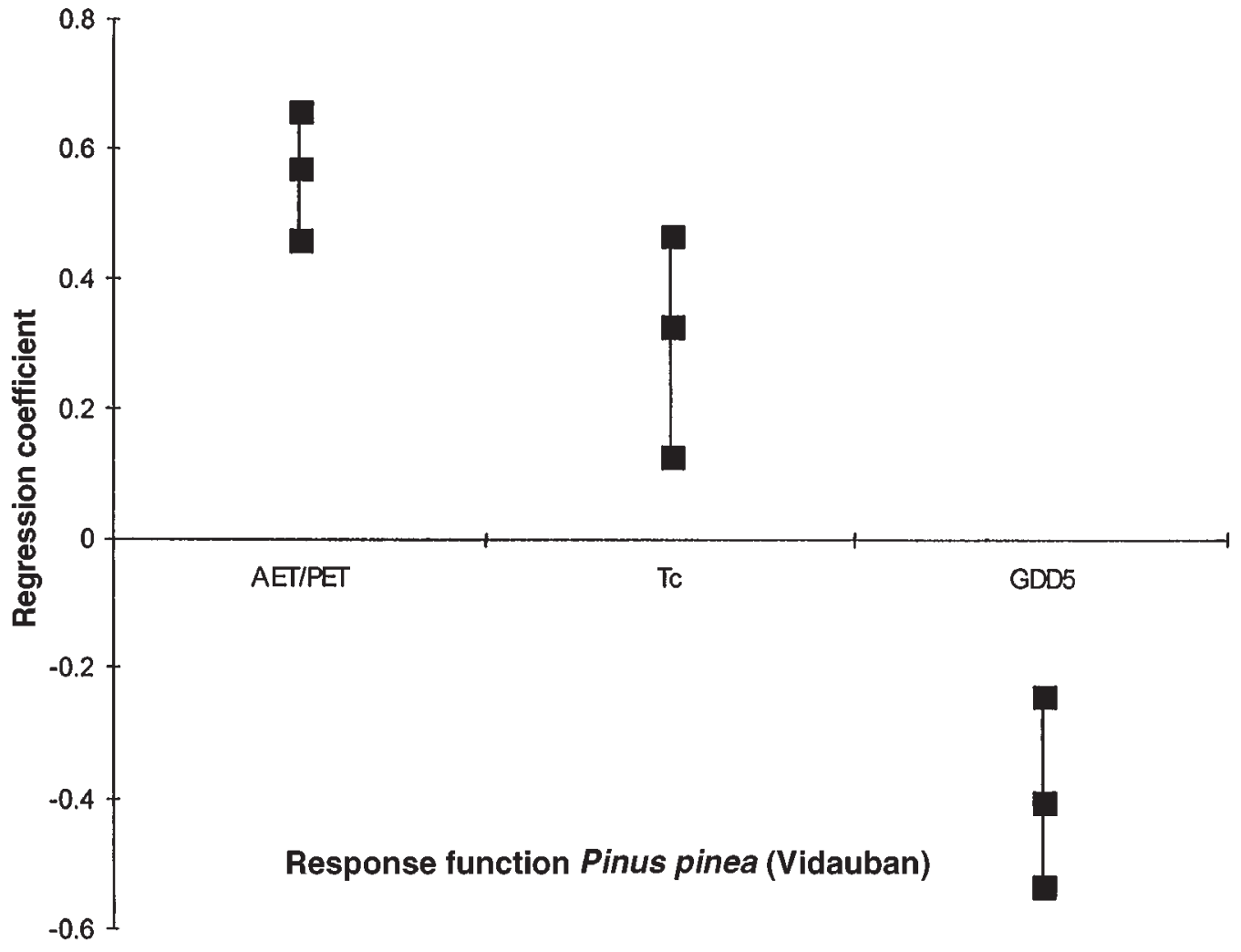

Table 1. Correlation between predicted and observed tree growth using 24 or 3 climatic variables with the bootstrap standard deviations.

\begin{tabular}{lll}
\hline Type of regression & Calibration & Verification \\
\hline 24 monthly variables & $0.94 \pm 0.032$ & $0.42 \pm 0.28$ \\
3 bioclimatic variables & $0.76 \pm 0.071$ & $0.66 \pm 0.17$ \\
\hline
\end{tabular}

Note: The calibration correlations were calculated from data randomly selected for the calibration, and the verification correlations were calculated from data not used for the calibration. The bootstrap standard deviations are calculated over 1000 simulations.

the predictors in the $i$ th observation, and $\epsilon_{i}$ is a random error term with mean $E\left(\epsilon_{i}\right)=0$ and variance $\sigma^{2}\left(\epsilon_{i}\right)=\sigma^{2}$, the covariance for all $i$ and $k ; i \neq k$.

We know that a "good model" respects two principles: parsimony of parameters and small deviations between observations and predictions (Bernier 1987). On one hand, the sophisticated models (i.e., the models having a lot of parameters) adjust well to any data set but often offer poor physical meaning. On the other hand, although they can delude when they are compared with observations, the sophisticated models may fail as soon as their output is quantitatively compared with an observation set.

To illustrate this parsimony principle, a response function has first been calculated as it is usually done by multiple regression after extracting principal components. The predictand is the mean tree-ring series, and the predictors are the 24 monthly climatic parameters (total precipitation and mean temperature from October of the previous year to September of the current year). These 24 predictors are reduced to a smaller number of principal components. To test the validity of such a complex model, we use a bootstrap method (Efron 1979, 1983), which consists in randomly selecting a great number of calibration sets among the observations to estimate the model parameters and to examine their variability. The nonselected observations are used in an independent verification (Guiot 1989). The number of replications is typically between 50 and 5000 (here 1000). The standard deviations of the mean regression coefficients and of the correlation estimates between predicted and actual growth are a clue of the predictive capability of the model.

Table 1 shows that the correlation is high over the calibration data set but is much smaller over the verification data set, greatly reducing the predictive capability of such a response function. The bootstrap method clearly shows that the complex model that fits the data well on the calibration sample does not provide any significant correlation when it is applied to independent data; the correlation of 0.42 is not significant at the $95 \%$ level.

By limiting the number of predictors we want to minimize the risk of making spurious predictions. Here, only three main bioclimatic parameters described above will be used. In this Mediterranean region, they are, by decreasing importance, the water availability represented by $\alpha, T_{\mathrm{c}}$, and $\mathrm{GDD}_{5}$.

These three parameters are used in a similar bootstrap regression. Table 1 shows clearly that, if the fit is apparently not as good as before on the calibration data, it is better and strongly significant on the independent data. Figure 1 shows that the tree-growth of $P$. pinea at Vidauban is favoured first by a high $\alpha$, second by a high $T_{\mathrm{c}}$ and then a low $\mathrm{GDD}_{5}$. The negative effect of $\mathrm{GDD}_{5}$ is likely to be also related to the summer evapotranspiration. The positive effect of $T_{\mathrm{c}}$ can be related to the limiting effect of exceptional low temperature in February or January.

Finally, estimates from the three bioclimatic parameters (Fig. 2) are close to the observations. The narrow error bars are certainly underestimated (because of the autocorrelation of the tree-ring series). The period 1950-1971 presents a low productivity except 
Fig. 2. Actual tree growth of Pinus pinea L. at Vidauban (dots) and estimates using a bootstrap regression from three bioclimatic variables. The central line gives the median calculated over 1000 simulations, and the two other lines give the $90 \%$ confidence interval.

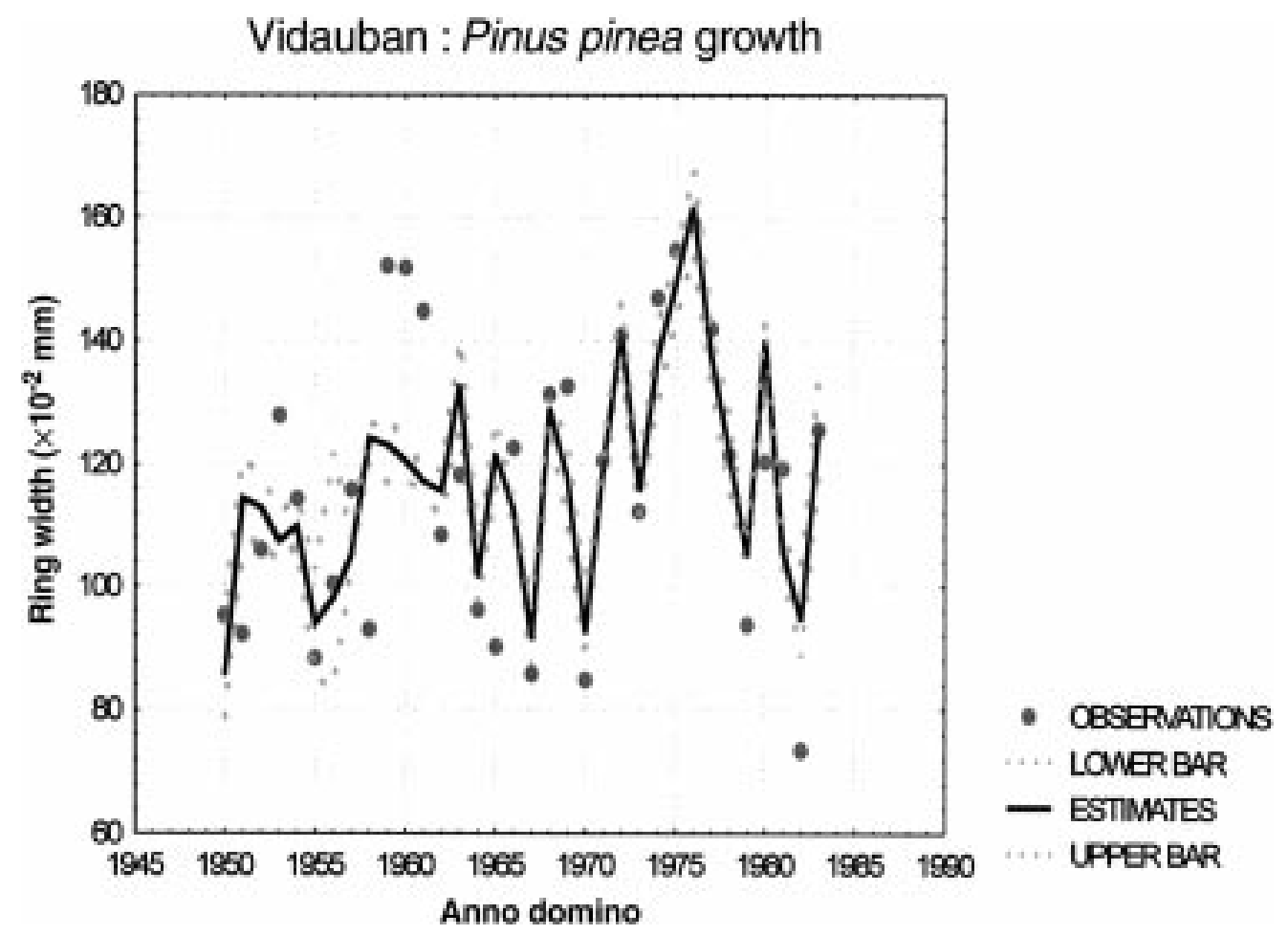

during 1959-1961, but the discrepancies between observations and estimates show that the higher productivity is not well modelled by the climatic parameters considered. On the contrary, the period of high productivity (1972-1980), appears to be clearly explained by the combination of climatic parameters involved in the response function. This contrast shows that the response function gives only the mean behaviour of the tree in relation to the climatic variable introduced to the regression. Other factors can be invoked to explain the discrepancies between data and estimates, such as the approximation used in the calculation of $\alpha$ and the water storage in the soil during the previous year. If it appears that $\alpha$ is the best explanatory variable, it is not easy to derive a exhaustive mechanistic interpretation from a unique response function.

\section{Criticism of classical regression and alternative proposal}

The utility of introducing another type of model is justified by the analysis of the underlying assumptions of classical regression. They are as follows (Neter et al. 1989): (i) the predictors are assumed to be nonrandom, although the general case where the predictors are random variables can be perfectly processed by introducing new hypotheses; (ii) the random error term cannot be correlated with predictors; (iii) the random error terms are uncorrelated random variables, although this problem can be solved using methods such Durbin-Watson, ARMA, etc., which need larger samples; and (iv) as a random variable can be ajusted by using a sample, the sample size must increase with the number of predictors (data sets of at least 20 observations in the univariate case). Of course this latter constraint can be released by introducing a priori knowledge.

Practically, all these assumptions are never completely fulfilled. To illustrate this point, the first assumption does not hold when data result from measurements of continuous quantities (Viertl 1997). For time-series data, the third assumption is often not appropriate; rather, the error terms are frequently serially correlated and lead to overestimate the model reliability. Lastly, confidence intervals estimated with few data points are too large to provide any useful information for predictive purposes. Clearly, there are many situations where the researcher should not use the classical linear regression, at least without introducing sophisticated considerations. Under those considerations, various other approaches have been developed, e.g., nonparametric regression techniques (kernel, local polynomial, spline.) (Fan and Gijbels 1996; Hastie and Loader 1993; Chu and Marron 1991), Bayesian methodology (Berger 1985), the Dempster-Shafer scheme (Caselton and Luo 1994), neural networks (Guiot and Tessier 1997), and fuzzy regressions (Tanaka et al. 1982; Heshmaty and Kandel 1985) based on the idea of fuzzy subsets (Zadeh 1973).

Fuzzy regression is a tool that has been developed to model situations in which hypotheses are uncertain and data are sparse and imprecise. As explained above, the applicability of classical statistical tools seem to be limited under such severe conditions. For instance, it is very well known that the population mean, $\mu$ (unknown but assumed to be constant), can be estimated using the sample average $\bar{x}$. Naturally, from sample to sample, we expect deviations between sample averages $\bar{x}$ and their target $\mu$. How do these deviations fluctuate? Classically the investigator computes a confidence interval centred on the sample average $\bar{x}$ with a radius $r$ to which a given probability (often $95 \%$ ) to include the unknown population parameter $\mu$ is assigned. In others words, in repeated sampling, the population mean $\mu$ will belong to the confidence interval $[\bar{x} \pm r] 95 \%$ of the time. It must be repeated that the confidence interval assessment requires some assumptions seldom fulfilled in environmental sciences. Indeed, hypotheses such as random sampling or statistical independence often cannot be assumed.

So, what can the environmentalist do? He may or may not take into account the violations of assumptions. The second attitude is not only unrealistic but also leads to unreliable predictions. The 
Fig. 3. Four fuzzy subsets to describe air temperature $\left({ }^{\circ} \mathrm{C}\right)$. An element $x$ in the universe of discourse $X$, here the real interval $5-35^{\circ} \mathrm{C}$, belongs to each fuzzy subset with a degree of truth between zero and one.

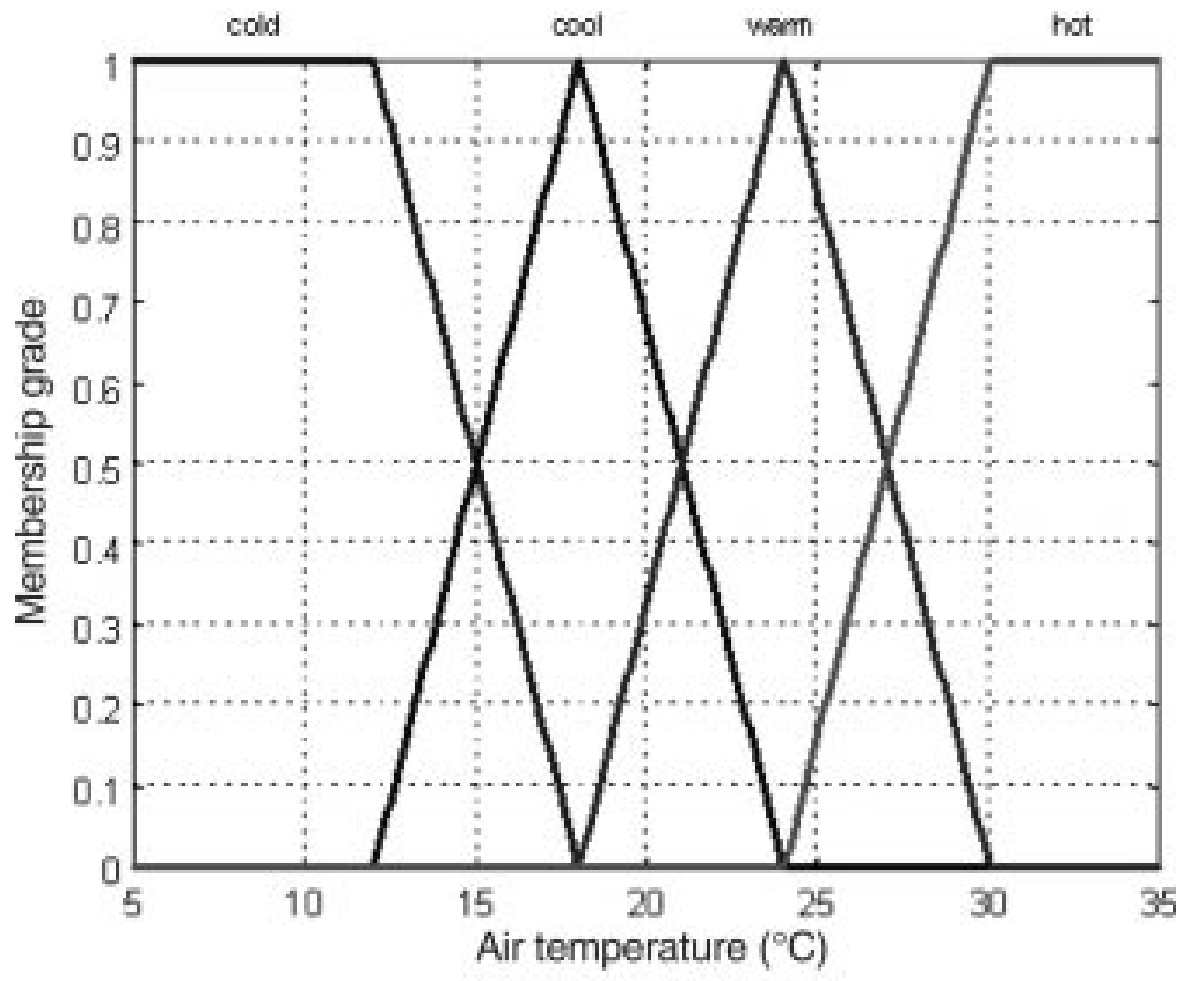

first attitude calls for unusual methods of which the difficulty level can be quite high for a majority of the practitioners. As an example, a Bayesian approach (Berger 1985; Bernier 1987) can offer robust analysis in environmental sciences; unfortunately, many environmentalists do not master it.

In others words, a skilled approach must also be workable or understandable. In this way, fuzzy techniques seem to offer a good compromise between "reliability" and "complexity." Since fuzzy regression operates with fuzzy numbers, we have to present the essential of fuzzy sets.

\section{Elementary concepts of fuzzy logic}

Fuzzy logic differs from conventional logic in that it aims at providing techniques for approximate rather than precise reasoning. Unlike classical probability, which is based on a frequency distribution in a random population, fuzzy logic deals with describing the characteristics of properties. Fuzzy logic describes properties that have continuously varying values by associating partitions of these values with a semantic label. The power of this approach comes from the fact that these semantic partitions can or even should overlap.

As an example, consider the parameter "air temperature." This parameter can be broken down into four subsets: "cold," "cool," "warm," and "hot." The interval from the smallest to the largest allowable value is called the universe of discourse denoted $X$. Here $X$ is the real interval from 5 to $35^{\circ} \mathrm{C}$ (Fig. 3).

Assume that the actual air temperature, say $x_{0}$, is $25^{\circ} \mathrm{C}$. We can see that $x_{0}$ belongs to the subset warm but also to the subset hot (Fig. 3). What is the difference? It lies in the so-called degree of membership. This particular value of air temperature $x_{0}=25^{\circ} \mathrm{C}$ belongs to the subset warm with a degree of truth equal to five of six, while it is only one of six for the subset hot. Moreover, $x_{0}$ does not belong either to the subset cold or to the subset cool. So, the degree of membership of $x_{0}$ is equal to zero for both.

Subsets like cold, cool, warm and hot are called fuzzy subsets of $X$ because each element $x$ of $X$ belongs to every subset with membership grade varying between zero and one. In other words, fuzzy logic is a graduated logic based on the idea of membership function from the universe of discourse $X$ to the real interval $[0,1]$. Each element $x$ of the universe of the discourse $X$ is associated with a real number between zero and one giving its degree of truth fulfilment to the subset being considered.

As a contrast, consider binary logic. We recall that an ordinary subset, say $E$, is always defined with respect to some universe of discourse $X$, which is itself an ordinary set. Any element $x$ of $X$ belongs or does not belong to the subset $E$, and the corresponding membership grade is one or zero; there is no place for an intermediate membership grade. Accordingly with the wording used in fuzzy logic, an ordinary set is called a "crisp" set. To distinguish between fuzzy and crisp concepts, fuzzy subsets will be denoted with a tilde $(\sim)$.

Assume $\tilde{A}$ is a fuzzy subset of $X$ with membership function $\mu_{A}(x)$. It must be emphasized that the universe of discourse $X$ is a crisp set, i.e., often the set of real numbers. On one hand, the open interval from its smallest to its largest value is called the "support" of $\tilde{A}$. On the other hand, the closed interval consisting of all elements with membership grade one is called the "core" of the fuzzy subset $\widetilde{A}$. Some fuzzy subsets have the empty set $\varnothing$ for core. If the core contains only one element this element is called the "pivot" of the fuzzy subset. Thus, any fuzzy subset $\widetilde{A}$ is completely defined by its membership function $\mu_{A}(x)$, which involves both support and core.

Often, the membership function $\mu$ can be broken down into two functions $L_{A}(x)$ and $R_{A}(x)$ corresponding to the "left" and "right" 
Fig. 4. Any LRFN, e.g., $\tilde{A} \equiv\{10,14,20,0.75,2.5\}$, is rigorously defined with five real numbers ordered as support lower end $\left(a_{-}=\right.$ $10)$, pivot $(a=14)$, support upper end $\left(a_{+}=20\right)$, left exponent $(p=0.75)$, and right exponent $(q=2.5)$ yielding the membership function $L_{A}(x)$ and $R_{A}(x)$ (see eq. 2). If we define a second LRFN, $\widetilde{B} \equiv\{11,15,21,0.5,4\}$, the sum is defined by eq. 3 ; for a particular $h=0.5$, it is $\widetilde{A}+\widetilde{B}=[12 .+14,18.5+20]_{h=0.5}$.

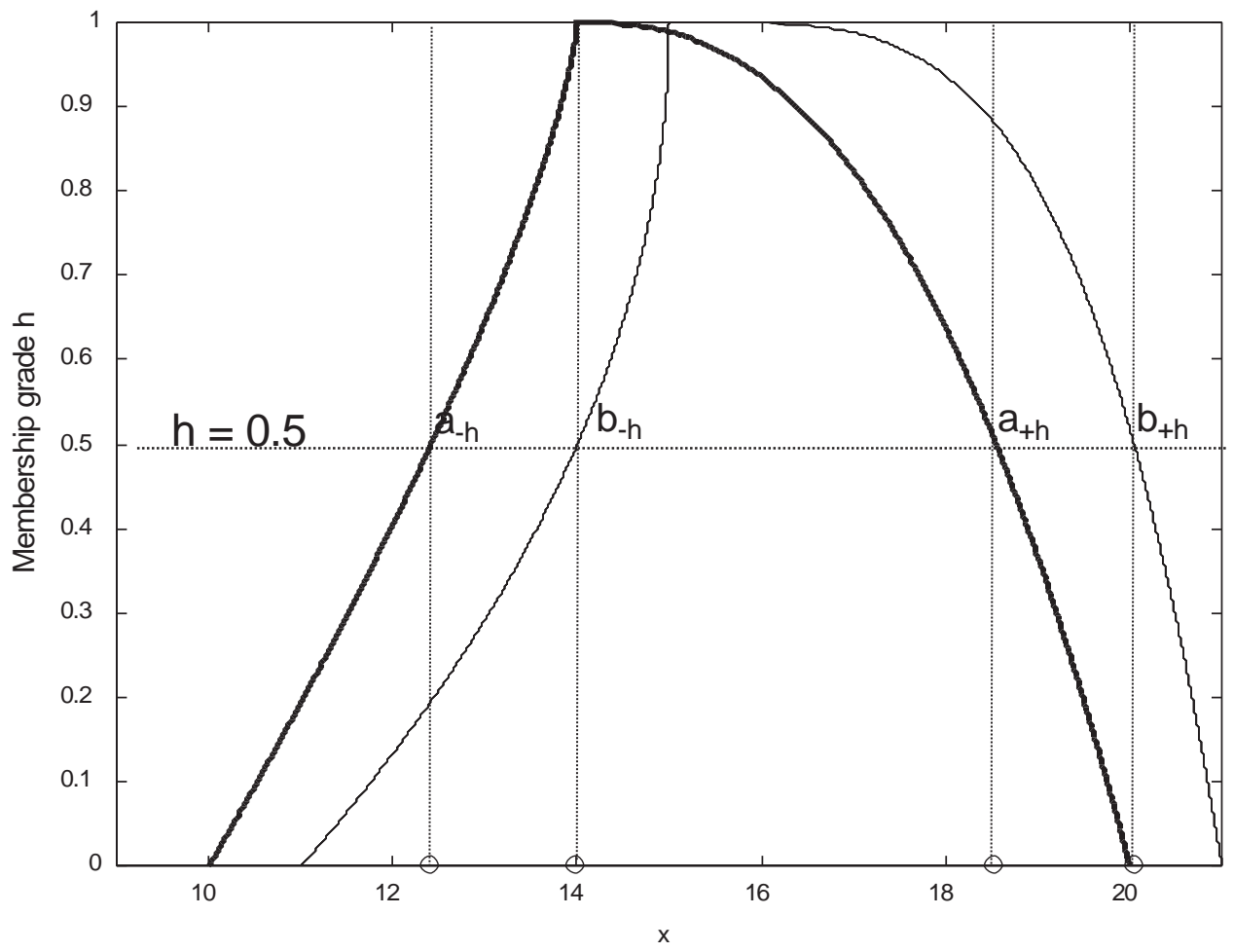

Table 2. Definitions of the fuzzy subsets $\widetilde{A} \equiv$ cold and $\widetilde{B} \equiv$ warm.

\begin{tabular}{|c|c|c|}
\hline & $\tilde{A} \equiv$ cold & $\widetilde{B} \equiv$ warm \\
\hline Support & ] $5,18[$ & ] $18,30[$ \\
\hline Core & {$[5,12]$} & $\{24\}$ (pivot) \\
\hline Left & No & $L_{B}:[18,24] \rightarrow[0,1]$ \\
\hline Right & $\begin{aligned} R_{A}:[12,18] & \rightarrow[0,1] \\
& x \mapsto R_{D}(x)=(30-x) / 6\end{aligned}$ & $\begin{aligned} x & \mapsto L_{b}(x)=(x-18) / 6 \\
R_{B}:[24,30] & \rightarrow[0,1] \\
x & \mapsto R_{D}(x)=(30-x) / 6\end{aligned}$ \\
\hline
\end{tabular}

sides. For instance, the fuzzy subsets cold and warm (Fig. 3, Table 2) are defined by a linear left and right function $(p=q=1)$.

\section{Fuzzy numbers}

Fuzzy numbers are special fuzzy subsets. Assume $\tilde{A}$ is a fuzzy subset of $X$ with membership function $\mu_{A}(x) . \tilde{A}$ is a fuzzy number if and only if $(i)$ the universe of discourse $X$ is the set of real numbers; (ii) at least one element $x$ of the support has its membership grade equal to one (normal assumption, i.e., the core exists); and (iii) the membership function has no local extrema (convex assumption).

The two latter properties limit the shape that a fuzzy number can take: it is always nondecreasing to the left of the core and nonincreasing to the right of the core. So, a real number can be seen as a fuzzy number whose support comprises only one element that has a membership grade equal to one.

The simplest type of fuzzy number has a triangular or trapezoidal membership function (Fig. 3, Table 2). It is convenient to introduce so-called left-right fuzzy numbers (LRFN) so as to be able to deal with curvilinear membership functions (Dubois and Prade 1980).

Assume a fuzzy number $\tilde{A}$ with support $] a_{-}, a_{+}[$, pivot $\{a\}$, and membership function $\mu_{A}(x)$. This latter can be broken down into $L_{A}(x)$ and $R_{A}(x)$ that have a simple analytic form:

$$
\mu_{A}(x)=\mid \begin{array}{ll}
L_{A}(x)=1-\left[(a-x) /\left(a-a_{-}\right)\right]^{p_{A}} & \left.x \in] a_{-}, a\right] \\
R_{A}(x)=1-\left[(x-a) /\left(a_{+}-a\right)\right]^{q_{A}} & x \in\left[a, a_{+}[\right. \\
0 & \text { otherwise }
\end{array}
$$

where both exponents $p_{A}$ and $q_{A}$ are positive real numbers giving a certain curvature to the selected membership function (Figs. 4 and 5). The subscript $A$ in eq. 2 and anywhere in the current text refers to the fuzzy number $\widetilde{A}$. It will be omitted if no confusion is possible.

Thus, eq. 2 defines an LRFN. Hence, any LRFN is rigorously defined with five real numbers ordered as support lower end, pivot, support upper end, left exponent, and right exponent (yielding the 
Fig. 5. The shape of any LRFN depends upon the exponents ( $p$, $q$ ) of its left-right membership functions: fat $\equiv(6,6)$; slim $\equiv$ $(0.4,0.4) ; \mathrm{TFN} \equiv(1,1)$ and $\mathrm{LRFN} \equiv(0.65,2.50)$. The first three panes show symmetric LRFN.
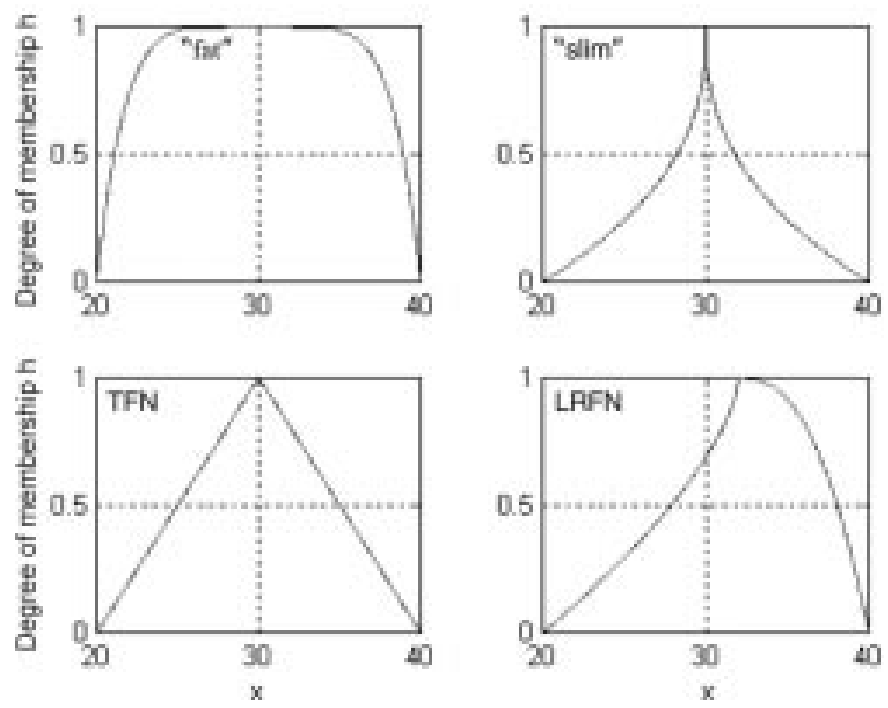

membership function). Any LRFN $\tilde{A}$ can thus be written as follows: $\tilde{A} \equiv\left\{a_{-}, a, a_{+}, p_{A}, q_{A}\right\}$ (Fig. 4). So, the LRFN concept allows us to represent not only the data but also some of the knowledge. As shown in Fig. 5, a large value for both exponents gives a "fat" fuzzy number, because each $x$ in its support is thought to be highly possible. In the opposite case, values less than one produce "slim" fuzzy numbers because only the elements $x$ near the pivot are thought to be highly possible. The linear case deals with $p=q=1$ (triangular fuzzy number or TFN).

\section{An example: evapotranspiration}

Evapotranspiration is the combined process of evaporation from both soil and plant surfaces and transpiration through plant surfaces. The AET/PET ratio is a physically meaningful index of water availability. Estimating the AET and PET of a vegetative surface is a very difficult and time-consuming task fraught with uncertainty (Burman and Pochop 1994). For instance, AET can be achieved with a lysimetric measurement and PET can be a model output (e.g., Penman formula). In all cases, results are uncertain, and these parameters can be seen as fuzzy numbers. For example, AET is given as $\widetilde{A} \equiv\left\{a_{-}, a, a_{+}, p_{A}, q_{A}\right\}=\{3,4,5,2,2\}$ and PET is given as $\widetilde{B} \equiv\left\{b_{-}, b, b_{+}, p_{B}, q_{B}\right\}=\{6,7,8,2,1 / 2\}$ (Fig. 6).

The AET/PET ratio is obtained by dividing two fuzzy numbers, but such division is not as straightforward as with real numbers (Kaufmann and Gupta 1991).

\section{Arithmetic operations on fuzzy numbers}

Given two fuzzy numbers, any fixed membership grade $h$ defines, for all $h \in[0,1]$, two closed intervals of real numbers (Fig. 4). In fact, each fuzzy subset, and thus also each fuzzy number, can be fully and uniquely represented by its interval strata called $h$-cuts in fuzzy terminology. Therefore, arithmetic operations on fuzzy numbers are defined in terms of arithmetic operations on their $h$-cuts, i.e., arithmetic operations on closed real intervals.

For short, any arithmetic operation on fuzzy numbers is performed for each level $h$ for all $0 \leq h \leq 1$. As the set of real numbers is linearly ordered, operations on closed real intervals are very easy using the following algorithm.

Consider two fuzzy numbers, say $\tilde{A}$ and $\tilde{B}$. Any level $h$ defines two closed real intervals respectively noted $\left[a_{-}, a_{+}\right]_{h}$ and $\left[b_{-}, b_{+}\right]_{h}$.
Fig. 6. The ratio of AET to PET is obtained by dividing two fuzzy numbers: AET (mm/day) $\equiv\{3,4,5,2,2\}$ and PET $(\mathrm{mm} /$ day $) \equiv\{6,7,8,2,0.5\}$. The fuzzy ratio $\tilde{a}=$ AET/PET is approximately a LRFN, that is $\tilde{a}=\{3 / 8,4 / 7,5 / 6, \approx 8 / 5, \approx 46 / 25\}$.
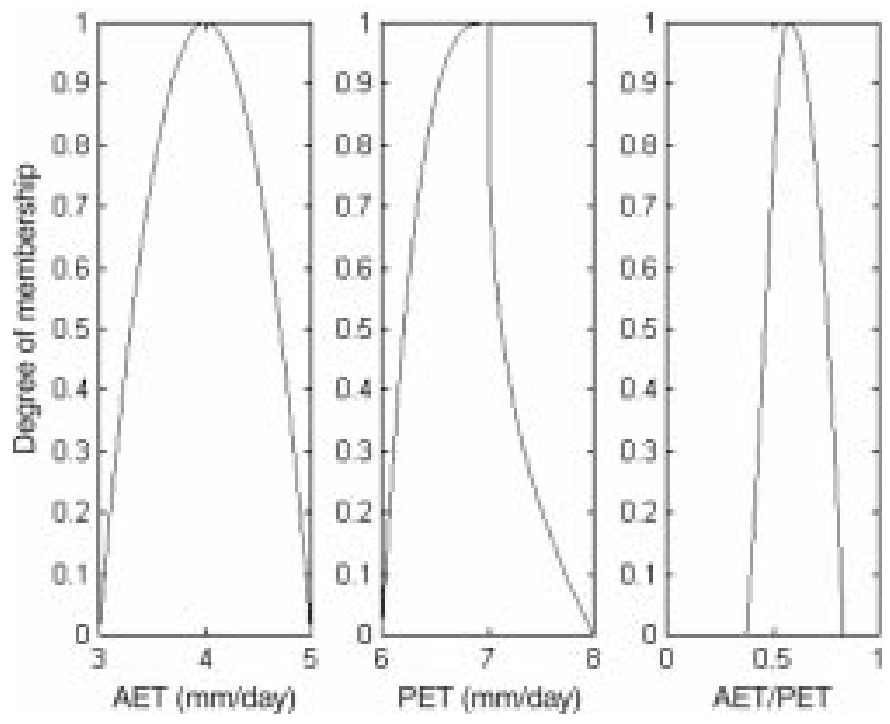

Let an asterisk denote any of the four basic arithmetic operations. The fuzzy number $\widetilde{C}=\widetilde{A} * \widetilde{B}$ is determined as follows. For all $h \in[0,1]$ :

[3]

$$
\left[c_{-}, c_{+}\right]_{h}=\left[a_{-}, a_{+}\right]_{h} *\left[b_{-}, b_{+}\right]_{h}
$$

where

$$
\begin{aligned}
& c_{-}=\min \left\{a_{-}^{*} b_{-}, a_{-}^{*} b_{+}, a_{+}^{*} b_{-}, a_{+}^{*} b_{+}\right\} \\
& c_{+}=\max \left\{a_{-} * b_{-}, a_{-}^{*} b_{+}, a_{+}^{*} b_{-}, a_{+}^{*} b_{+}\right\}
\end{aligned}
$$

with a restriction for the division that the denominator closed interval cannot contain zero.

As sketched in Fig. 6, the AET/PET ratio is a fuzzy number that can be approximated by the LRFN $\tilde{\alpha}=\{3 / 8,4 / 7,5 / 6, \approx 8 / 5$, $\approx 46 / 25\}$ the exponents $p$ and $q$ resulting from a numerical approximation (not shown here). In general, arithmetic operations on fuzzy numbers generally do not preserve the LRFN type (Dubois and Prade 1980; Kaufmann and Gupta 1991). However, standard minimization numerical methods can provide approximate values for membership function exponents.

\section{Measure of fuzziness}

The concept of information is closely connected to the concept of uncertainty. Since Zadeh (1965) first introduced the concept of fuzzy subset, various authors have attempted to define measures of fuzziness of a fuzzy subset. For the most part these have been influenced by Shannon's measure of entropy. As a result, the fuzziness of any fuzzy number can be defined by the membership function area, that is, the area defined by its support and membership function.

Let $\widetilde{A} \equiv\left\{a_{-}, a, a_{+}, p_{A}, q_{A}\right\}$ be a LRFN defined by eq. 2 and $U_{A}$, be the measure of its fuzziness. Because we deal with LRFN, the area under the membership function is simply:

$$
U_{A}=\int_{a-}^{a+} \mu_{A}(x) \mathrm{d} x=\int_{a-}^{a} L_{A}(x) \mathrm{d} x+\int_{a}^{a+} R_{A}(x) \mathrm{d} x
$$

Substituting eq. 2 in eq. 4 , the fuzziness $U_{A}$ of any LRFN $\tilde{A} \equiv$ $\left\{a_{-}, a, a_{+}, p_{A}, q_{A}\right\}$ is 
Table 3. The characteristic classes of the ratio $(\alpha)$ of actual evapotranspiration (AET) to potential evapotrasnpiration (PET) and the corresponding values of tree growth of Pinus pinea L. at Vidauban.

\begin{tabular}{lrrrl}
\hline$\alpha$ & $G_{1}$ & $G_{2}$ & $G_{3}$ & $\Delta G$ \\
\hline 47.0 & 74 & 86 & 95 & 21 \\
57.3 & 94 & 106 & 116 & 22 \\
59.3 & 92 & 112 & 133 & 41 \\
62.5 & 114 & 127 & 152 & 38 \\
67.4 & 90 & 125 & 152 & 62 \\
74.1 & 106 & 128 & 142 & 36 \\
83.7 & 118 & 139 & 159 & 41 \\
\hline
\end{tabular}

Note: Tree growth is a triangular fuzzy number (TFN) with the open interval $] G_{1}, G_{3}\left[\right.$ as support and $\left\{G_{2}\right\}$ as pivot. The spread of the TFN is $\Delta G=G_{3}-G_{1}$.

$$
U_{A}=\delta_{A} \frac{p_{A}}{1+p_{A}}+\eta_{A}(x) \frac{q_{A}}{1+q_{a}}
$$

where $\delta_{A}=a-a_{-}$and $\eta_{A}=a_{+}-a$ are the left and right spread of the LRFN $\tilde{A}$.

In the triangular case $\left(p_{A}=q_{A}=1\right)$, the fuzziness simply is the area of a triangle with height unity, that is, $0.5\left(a_{+}-a_{-}\right)=0.5\left(\delta_{A}+\right.$ $\left.\eta_{A}\right)$. According to eq. 5 , the fuzziness AET/PET is found to be 0.29 .

\section{The linear fuzzy regression is a linear programming problem}

The fuzzy regression aims to envelop the limited observations for the case when the control $X$ is crisp and the vagueness of the response $Y$ is described in terms of fuzzy numbers. This technique makes it possible to take into account not only the uncertainty in the response but also that stemming from the selected relationship. In addition, deviations between the observed values and the estimated values (i.e., the errors) are fully taken into account by the fuzziness of the coefficients. It contrasts to the usual classical regression analysis where deviations are supposed to be caused by observation errors only, if we assume that the specified model is correct.

Finding the coefficients of a fuzzy regression leads to a so-called linear programming (LP) problem (Bardossy et al. 1990; Boreux et al. 1997).

Let a sample of $T$ observations be $x_{t}, \tilde{y}_{t}, t=1,2, \ldots, T$. A univariate fuzzy linear regression can be written as follows (the general multivariate case is a simple extension of the basic ideas developed hereafter):

$$
\tilde{z}_{t}=\tilde{a}_{0}+\tilde{a}_{1}\left(x_{1}-r\right) \quad \text { with } \quad 1 \leq t \leq T
$$

in which $\tilde{z}_{t}$ is the estimated fuzzy response to the crisp control $x_{t}$, $\tilde{a}_{0}$, and $\tilde{a}_{1}$ are the fuzzy coefficients to be calculated and $r$ is a reference point, i.e., a particular value of the control $X$ for which the fuzziness of the response is assumed to be the smallest.

Since, the sample size $T$ is assumed to be small, say less than about 10 in the univariate case, eq. 6 does not include any outliers (such a concept has no sense with a so low number of data).

Although the fuzzy regression problem (eq. 6) can be solved using any type of fuzzy numbers, we will limit ourselves to the LRFN type $\tilde{A} \equiv\left\{a_{-}, a, a_{+}, p_{A}, q_{A}\right\}$. As seen previously, any $h$-cut defines a closed interval on the real set with $a_{-}(h)$ and $a_{+}(h)$ as lower and upper bounds derived from eq. 2 :

$$
\begin{aligned}
& a_{-}(h)=a-\delta_{A}(1-h)^{1 / p_{A}} \\
& a_{+}(h)=a+\eta_{A}(1-h)^{1 / q_{A}}
\end{aligned}
$$

where $\delta_{A}=\underset{\sim}{a}-a_{-}$and $\eta_{A}=a_{+}-a$ are the left and right spread of the LRFN $\tilde{A}$.

Consequently if $\tilde{y}_{t}, \tilde{a}_{0}$, and $\tilde{a}_{1}$ are LRFN then $\tilde{z}_{t}$ is also a LRFN making the solution of problem (eq. 6) very simple using eqs. 5 and 7 .

\section{First step: the objective function}

It seems rational to seek fuzzy coefficients $\tilde{a}_{0} \equiv\left\{a_{0-}, a_{0}, a_{0+}\right.$, $\left.p_{a 0}, q_{a 0}\right\}$ and $\tilde{a}_{1} \equiv\left\{a_{1-}, a_{1}, a_{1+}, p_{a 1}, q_{a 1}\right\}$ that possess minimum fuzziness (eq. 5). Therefore, an objective function to be minimized could be the average fuzziness of both coefficients:

$$
f\left(\tilde{a}_{0}, \tilde{a}_{1}\right)=\frac{U_{a 0}+U_{a 1}}{2}
$$

The fuzzy coefficients $\tilde{a}_{0}$ and $\tilde{a}_{1}$ could thus be found by minimizing eq. 8 under a set of linear constraints, as explained in the next subsection.

Another objective function often used is the theoretical surface defined by the searched coefficients being sought, which is claimed to be a more efficient procedure (Bardossy et al. 1990) but appears to be less understandable intuitively. We will nevertheless use it below.

\section{Second step: the constraints}

Recall that any $h$-cut defines a closed interval on a LRFN, such that the endpoints of this interval are given by eq. 7. As before it is rational to require that the calculated or estimated intervals (referred to as $\tilde{z}_{t}$; eq. 6) include the observed intervals (referred to as $\left.\tilde{y}_{t}\right)$.

Hence, for any level $h(0 \leq h \leq 1)$, at each measurement point $(0 \leq t \leq T)$, there correspond two linear inequality constraints based on the requirement that the width of the observed fuzzy number $\tilde{y}_{t}$ must be included within the width of the predicted fuzzy number $\tilde{z}_{t}$. So, for all $t(0 \leq t \leq T)$ :

$$
\begin{aligned}
& \text { if }\left(x_{t}-r\right) \geq 0 \quad\left\{\begin{array}{l}
a_{0-}(h)+a_{1-}(h) \cdot\left(x_{t}-r\right) \leq y_{t-}(h) \\
a_{0+}(h)+a_{1+}(h) \cdot\left(x_{t}-r\right) \geq y_{t+}(h)
\end{array}\right. \\
& \text { if }\left(x_{t}-r\right)<0 \quad\left\{\begin{array}{l}
a_{0-}(h)+a_{1+}(h) \cdot\left(x_{t}-r\right) \leq y_{t-}(h) \\
a_{0+}(h)+a_{1-}(h) \cdot\left(x_{t}-r\right) \geq y_{t+}(h)
\end{array}\right.
\end{aligned}
$$

In addition by definition, the spreads of each fuzzy coefficient are positive:

$$
\begin{aligned}
& a_{0}-a_{0-} \geq 0 \\
& a_{0+}-a_{0} \geq 0 \\
& a_{1}-a_{1-} \geq 0 \\
& a_{1+}-a_{1} \geq 0
\end{aligned}
$$

We have to add some constraints involving the exponents, that is $p_{a 0}, q_{a 0}, p_{a 1}$, and $q_{a 1}$. In fact they are expressed in term of equality constraints, which do not depend upon the data. Their values stem from the physics of the problem. In others words, the shape of each fuzzy coefficient to be found is to be selected by the practitioner.

To sum up, in the univariate case, a linear fuzzy regression involving $T$ data leads to the minimization of a linear objective function subject to $2 T+4$ linear inequality constraints. 
Fig. 7. Observed (squares) and estimated (lines) tree growth of Pinus pinea L. at Vidauban. The estimates are obtained from a classical linear regression (LR) model (lower graph) and from a fuzzy LR model with $h=0.5$ and $h=0.75$ (upper graph). The observations are represented by squares. LR estimates are presented with $95 \%$ confidence intervals.
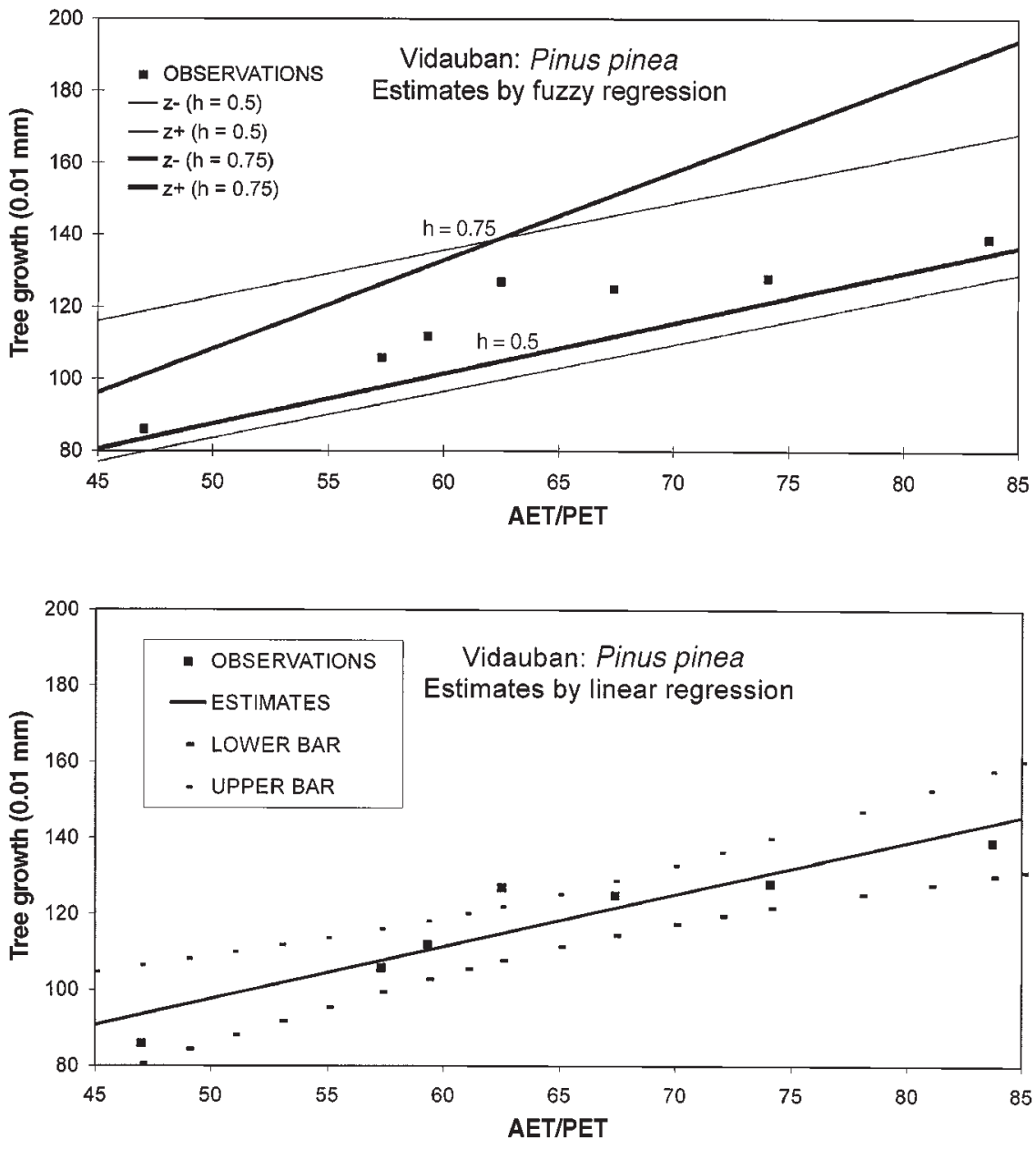

\section{Results}

According to the parsimony principle and foundations of fuzzy logic (where a priori knowledge is most important), we will apply the fuzzy regression technique to tree growth using one climatic variable. Figure 1 shows that the main predictor is $\alpha$. For a given value of $\alpha$, we can have varying dispersion of tree growth, so that we assume that tree growth is a fuzzy function of $\alpha$. The membership function of tree growth $(\widetilde{y})$ is constructed as follows:

(1) the 34 observations between 1950 and 1983 are ordered from the lowest value of $\alpha(43 \%)$ to its highest (91\%);

(2) seven classes of five observations (except the last one, which has four observations) are defined over the range of $\alpha$; and

(3) each class is represented by the mean of $\alpha$, the mean $G_{2}$ (pivot) of the tree growth, minimum $G_{1}$ and maximum $G_{3}$ of tree-growth in the given class (Table 3); $G_{1}$ and $G_{3}$ define the support of the observed fuzzy numbers $\tilde{y}_{t}$.

On one hand, $\mathrm{G}_{2}$ varies almost linearly with $\alpha$ (correlation $=0.93$ : see Fig. 7), which justifies a posteriori the use of $\alpha$ as the main driving factor of the tree growth. For the lowest values of $\alpha(<59 \%)$, the growth range is about 20 and for the largest ones (>59), it is between 35 and 60 . This sug- gests also that other secondary factors must be involved, which are ignored here. The tree-growth variable is considered, for simplicity and in absence of objective reasons for another solution, as a triangular fuzzy number $\left(G_{1}, G_{2}, G_{3}\right)$. On the other hand, $\alpha$ can be seen as a nonfuzzy (or crisp) number, because the uncertainty associated to its measurement is ignored as it is much smaller than the uncertainty of the relationship between $G$ and $\alpha$.

The lowest ranges obtained for the highest water stresses also indicate the pertinence of the limiting factor principle. As mentioned before, the fuzzy regression uses a reference value for which the tree growth is evaluated with maximum precision. From this limiting factor principle, it is clear that the reference point corresponds to very low $\alpha$. According to the biome model of Prentice et al. (1992), neither forest nor shrubland can exist below $\alpha \approx 30 \%$. We thus take this value as reference $r$, and eq. 6 can be written (recalling that $z$ refers to the estimate and $y$ to the observation):

$$
\tilde{z}_{t}=\tilde{a}_{0}+\tilde{a}_{1}\left(\alpha_{i}-30\right)
$$

where $\tilde{z}_{t}$ is the predicted fuzzy number corresponding to the $i$ th observation and $\tilde{a}_{0}$ and $\tilde{a}_{1}$ are the parameters to be found. The fact that a value of $r=30$ is outside the data range is 
Table 4. Fuzzy linear regression between the crisp input variable $\alpha \equiv$ AET/PET and the fuzzy (TFN) output variable $\tilde{y} \equiv$ tree growth.

\begin{tabular}{|c|c|c|c|c|c|c|c|c|c|c|}
\hline \multirow[b]{2}{*}{$h$} & \multicolumn{5}{|l|}{$\underline{\tilde{a}_{0}}$} & \multicolumn{5}{|l|}{$\tilde{a}_{1}$} \\
\hline & $a_{0-}$ & $a_{0}$ & $a_{0+}$ & $p_{a 0}$ & $q_{a 0}$ & $a_{1-}$ & $a_{1}$ & $a_{1+}$ & $p_{a 1}$ & $q_{a 1}$ \\
\hline 0.50 & 18.5 & 96.6 & 96.6 & 1 & 1 & 1.3 & 1.3 & 1.3 & 0.2 & 5 \\
\hline 0.75 & 59.5 & 59.5 & 59.5 & 1 & 1 & 1.4 & 1.4 & 2.6 & 0.2 & 5 \\
\hline
\end{tabular}

Note: The fuzzy parameters are LRFN with fixed left right membership functions. The LP problem is solved for two levels of $h$.

not really a problem, as a value this extreme, such as a value with a null error bar, is not really observable.

To use eq. 11 in the calculations, select any level $h$ in $[0$, 1] and rewrite eq. 11 in interval form $(\alpha>r=30)$ taking account of eq. 7 :

$$
\begin{aligned}
& z_{-}(h)=a_{0}-\delta_{a 0}(1-h)^{1 / P_{a 0}}+\left[a_{1}-\delta_{a 1}(1-h)^{1 / P_{a 1}}\right](\alpha-r) \\
& z_{+}(h)=a_{0}+\eta_{a 0}(1-h)^{1 / q_{a 0}}+\left[a_{1}+\eta_{a 1}(1-h)^{1 / q_{a 1}}\right](\alpha-r)
\end{aligned}
$$

Note that some confusion may remain between the credibility level $h$ applied to solve the LP problem (i.e., the $h$ value for which we compute the fuzzy numbers $\tilde{a}_{0}$ and $\tilde{a}_{1}$ ) and the level $h$ used to represent them in interval terms as written in eq. 12. It will be discussed below.

The minimization of the linear objective function subject to linear constraints constitutes a so-called LP problem. In this LP problem, the profile of the membership function of the coefficients and dependent variable is to be selected. The $\tilde{y}_{t}$ have already been taken as triangular fuzzy numbers. We make the same choice for $\tilde{a}_{0}$. To take account of the fact that low values of $\alpha$ are much more constraining than high values, we choose an asymmetric membership function for $\tilde{a}_{1}$ defined by the equation with $p=0.2$ (with a small area) and $q=5$ (with a larger area).

The grade $h$ is specified to solve the LP problem, which then yields equations for $z_{-}$and $z_{+}$that are functions of any $\mathrm{h}$, and then $h$ is chosen as a particular value to provide the results. We give them in Table 4 for two levels of $h$. At $h=0.50$, the LP problem yields a triangular fuzzy number $\tilde{a}_{0}$ and a crisp $\tilde{a}_{1}$. At $h=0.75$, the LP problem gives a crisp $\tilde{a}_{0}$ and $\tilde{a}_{1}$ as an LRFN. From eq. 12 these results can be written as follows:

$$
\begin{aligned}
& h=0.5 \Rightarrow\left\{\begin{array}{l}
z_{-}=96.6-78.1(1-h)+1.3(\alpha-30) \\
z_{+}=96.6+1.3(\alpha-30)
\end{array}\right. \\
& h=0.75 \Rightarrow\left\{\begin{array}{l}
z_{-}=595+1.4(\alpha-30) \\
z_{+}=595+\left[1.4+1.2(1-h)^{1 / 5}\right](\alpha-30)
\end{array}\right.
\end{aligned}
$$

The predictions obtained by these equations are displayed in Fig. 7, which calls for the following comments.

(1) As pointed out before, the credibility level from which the LP problem has been solved should not be confused with the level $h$ used to sketch the results. Here we solved the LP problem for $h=0.5$ and $h=0.75$ while we drafted the figure with $h=0.5$. (This value must be lower or equal to the value of $h$ for which the minimization has been done.)

(2) The LP problem for $h=0.5$ returns two parallel straight lines meaning that the uncertainty does not depend upon the ratio $\alpha$. Of course such a conclusion stems from the fact that the coefficient $\tilde{a}_{1}$ has been found crisp, but there is no physical argument to support this result.

(3) The LP problem for $h=0.75$ envelops the input points between two divergent straight lines indicating that the uncertainty increases with the distance from the reference point. This result is in accordance with our interpretation of the problem: low values of $\alpha$ limit tree-growth, while other factors are limiting for high values of $\alpha$; this increases the uncertainty of the prediction using only $\alpha$.

(4) The classical linear regression (LR) provides predictions closer to the lower limit of those provided by the fuzzy regression, but the narrowest error bars are obtained for values close to the mean climate, even if a mean $\alpha$ is certainly less limiting for the growth than a low $\alpha$. The consequence of the asymmetry of the fuzzy number $\left(G_{1}\right.$, $G_{2}, G_{3}$ ) constructed to take into account the limiting factor principle is certainly closer to the biology of the problem.

\section{Discussion}

\section{Comparison with classical approach}

The fuzzy approach gives results comparable with those obtained using a classical linear regression. Furthermore, the fuzzy approach selects the same variable as limiting factor as the classical linear regression. However, ordinary classical regression does not give any information about which values of the environmental parameters are the most limiting. The classical response function just tells us that, on average, a low $\alpha=$ AET/PET limits the growth and a high $\alpha$ favours the growth.

Furthermore, classical response functions have proved to be particularly efficient for trees growing in such drastic conditions that the limiting factor is unique throughout the year and from year to year. Such situations induce a high variability in tree-ring width and define sensitive trees in opposition to complacent trees characterized by ring-width series without any variability. In fact, this situation can also be contrasted to situations were growth is limited by the fluctuations of multiple limiting factors whose combination varies during the year and from year to year. Such situations induce a high variability of ring width and correspond also to sensitive trees. In this situation, the classical response function provides poor information because of the nonstationarity of the combination of potential explicative variables. We can assume that the use of fuzzy regression will provide information about the threshold about which a parameter is involved in the control of tree growth. The fuzzy approach enables one to test separately the different variables after an 
a priori selection of these variables on the basis of the understanding of the tree environment (climate, elevation, substratum). This would be a first step in the construction of a type of "growth simulator" adapted to the different environments of a given species.

\section{Specific advantages of fuzzy linear regression}

The first remarkable point in the results given by the fuzzy response function is that the concept of limiting factor seems to be taken into account much more strongly. The interval of credibility given by the fuzzy regression suggests that better growth predictability is obtained for high water stress (i.e., low values of $\alpha$ ), which is typical of Mediterranean climate. This information was included into the model a priori by selecting the reference value of $\alpha=30$, but it has been confirmed a posteriori by the results (see eq. 6). For higher values $(>65 \%), \alpha$ loses the status of limiting factor and the error intervals become larger. By comparison, the classical regression seems to give a better precision for values close to the mean climate, which is far from the biology of the problem.

Next, fuzzy regression can be also a method to test different hypotheses on several potential predictors when any further experimental approach is quite impossible, as it is for testing response models in risk analysis at very low doses (Bardossy et al. 1993) or for trees in their natural environment. Several tests can be envisaged.

(1) For a unique population, when different climatic variables are correlated with tree growth (as shown by a preliminary linear regression), these variables can be introduced in turn as unique predictors into a fuzzy model to identify which values are the most limiting; this can be done by changing the reference value and the membership function profile.

(2) The same potential explanatory variable $\alpha$ could be tested for different populations selected by modifying the threshold for which this parameter remains limiting. Such a procedure could be implemented for example on the basis of edaphic characteristics or elevation in the same climatic area.

\section{Weaknesses of fuzzy linear regression}

The practitioners of fuzzy linear regression claim that it is a robust form of regression. However, it has been shown (Redden and Woodall 1996) that (i) fuzzy linear regression is sensitive to outliers; (ii) the fuzzy linear algorithm cannot take all of the the available information into account (redundant constraints in the LP problem); and (iii) the algorithm can produce crisp coefficients. (A crisp coefficient occurs when the width of the fuzzy regression coefficient is 0 .)

The first two remarks are not specific to fuzzy linear regression. Ordinary least squares and orthogonal least squares are all known to be sensitive to outliers and influential points. That is why we explicitly removed any outlier. With regard to the available information, the constrained optimization involves inequalities that can be redundant. In any case, the relevance of constrained optimization in decision making is not in question. With regard to crisp coefficients, the fuzzy linear algorithm really can produce crisp coefficients. The reason is that we seek fuzzy coefficients that possess minimum fuzziness. All the same, as soon as at least one coefficient is not crisp, the response is clearly fuzzy.

Another issue is the interpretation of the predicted fuzzy numbers. How does a practitioner measure the relevance of its fuzzy response function? How does a practitioner decide whether or not to add an explanatory variable in the fuzzy linear regression? This issue is not as yet resolved.

Nevertheless, we claim that the environmentalist has three reasons to consider fuzzy linear regression. The first results from the realization that it is often not realistic to assume that a crisp function represents the relationship between the given variables. The second comes from the nature of data, which in environmental sciences are inherently fuzzy. The third reason is that the fuzzy concepts are very intuitive making the practitioner more responsible over its own background and field of study.

\section{Conclusions}

Often in environmental sciences we are confronted with uncertain facts and scarce and imprecise data. For instance, some environmental experiments cannot be repeated a lot of time because they are very expensive and (or) destructive. In that case the response $Y$ to the control $X$ is often doubtful. As an alternative to classical regression, fuzzy linear regression was introduced (Tanaka et al. 1982).

A fuzzy regression aims to envelop the limited observations for the case when the control $X$ is crisp and the vagueness of the response $Y$ is described in terms of fuzzy numbers. This technique makes it possible to take into account not only the uncertainty in the response but also that stemming from the selected relationship. In addition, deviations between the observed values and the estimated values (i.e., the errors) are fully taken into account by the fuzziness of the coefficients. The fuzzy response function thus appears to be an approach between the mechanistic and the statistical descriptive approaches.

\section{Acknowledgements}

This study was made possible thanks to support provided by the cooperation program between the Commissariat général aux relations internationales de la Communauté française de Belgique, the Fond national de la recherche scientifique, and the Centre national de la recherche scientifique. We are grateful to Professor Lucien Duckstein, University of Arizona, and the École nationale du génie rural, des eaux et des forêts, Paris, France, who corrected and commented on the manuscript.

\section{References}

Badeau, V., Dupouey, J.L., Becker, M., and Picard, J.F. 1995. Long-term growth trends of Fagus sylvatica L. in northeastern France. A comparison between high and low density stands. Acta Oecol. 16: 571-583.

Bardossy, A., Bogardi, I., and Duckstein, L. 1990. Fuzzy regression in hydrology. Water Resour. Res. 26: 1497-1508.

Bardossy, A., Duckstein, L., and Bogardi, I. 1993. Fuzzy non-linear regression analysis of dose response relationship. Eur. J. Oper. Res. 66: 36-51. 
Berger, J.O. 1985. Statistical decision theory and Bayesian analysis. Springer-Verlag, New York.

Bernier, J. 1987. Elements of Bayesian analysis of uncertainty in hydrological reliability and risk models. In Engineering reliability and risk in water resources. Edited by L. Duckstein and E. Plate. Martinus Nijhoff, Boston, Mass. pp. 405-421.

Bert, G.D. 1992. Influence du climat, des facteurs stationnels et de la pollution sur la croissance et l'état sanitaire du sapin pectiné (Abies alba) dans le jura. Ph.D. thesis, Université de Nancy, Nancy, France.

Boreux, J.J., Pesti, G., Nicolas, J., and Duckstein, L. 1997. Age model estimation in paleoclimatic research: fuzzy regression and radiocarbon uncertainties. Palaeogeogr. Palaeoclim. Palaeoecol. 128: 29-37.

Burman, R., and Pochop, L. 1994. Evaporation, evapotranspiration and climatic data. Dev. Atmos. Sci. No. 22.

Caselton, W.F., and Luo, W. 1994. Inference and decision under near ignorance conditions. Engineering risk in natural resources management with special references to hydrosystems under changes of physical or climatic environment. Edited by $\mathrm{L}$. Duckstein and E. Parent. Kluwer Academic Publishers, Dordrecht, the Netherlands. pp. 291-303.

Chu, C., and Marron, J. 1991. Choosing a kernel regression estimator (with discussion). Stat. Sci. 6: 404-436.

Cropper, J.P. 1982. Comment on response functions. In Climate from tree-rings. Edited by M.K. Hughes, P.M. Kelly, J.R. Pilcher, V.C. LaMarche Jr. Cambridge University Press, Cambridge, U.K. pp. 38-45.

Douglass, A.E. 1936. Climatic cycles and tree-growth. Vol. 3. A study of cycle. Carnagie Inst. Wash. Publ. No. 289.

Dubois, D., and Prade, H. 1980. Fuzzy sets and system theory and applications. Academic Press, San Diego, Calif.

Efron, B. 1979. Bootstrap methods: another look at the jackknife. Ann. Stat. 7: 1-26.

Efron, B. 1983. Estimating the error rate of a prediction rule: improvement on cross-validation. J. Am. Stat. Assoc. 78: 316-331.

Emberger, L. 1930. La végétation de la région méditerranéenne. Essai d'une classification des groupements végétaux. Rev. Gen. Bot. 42: 641-662 and 705-721.

Fan, J., and Gijbels, I. 1982. Local polynomial modelling and its applications. Chapman \& Hall, London, U.K.

Federer, C.A. 1982. Transpirational supply and demand: plant, soil, and atmospheric effects evaluated by simulation. Water Resour. Res. 18: 355-362.

Fritts, H.C. 1976. Tree-rings and climate. Academic Press, London, U.K.

Fritts, H.C. 1982. The climate growth response. In Climate from tree-rings. Edited by M.K. Hughes, P.M. Kelly, J.R. Pilcher, V.C. LaMarche Jr. Cambridge University Press, Cambridge, U.K. pp. 38-45.

Fritts, H.C., Blasing, T.J., Hayden, B.P. and Kutzbach, J.E. 1971. Multivariate techniques for specifying tree-growth and climate relationships and for reconstructing anomalies in paleoclimate. J. Appl. Meteorol. 10: 845-864.

Gadbin-Henry, C. 1994. Études dendroécologiques de Pinus pinea L. Aspects méthodologiques. Ph.D. thesis, Université d'Aix-Marseille III, Aix-en-Provence, France.

Guiot, J. 1989. Method of calibration and comparison of methods. In Methods of dendrochronology. Edited by E.R Cook. and L.A Kairiukstis. Kluwer Academic Publishers and International Institute for Applied Systems Analysis, Dordrecht, the Netherlands. pp. 165-178 and 185-193.
Guiot, J., and Tessier, L. 1997. Detection of pollution signals in tree-ring series using AR processes and neural networks. In Applications of time-series analysis in astronomy and meteorology. Edited by T.S. Rao, M.B. Priestley, and O. Lessi. Chapman \& Hall, London, U.K. pp. 413-426.

Guiot, J., Berger, A.L., and Munaut, A.V. 1982a. Response functions. In Climate from tree-rings. Edited by M.K. Hughes, P.M. Kelly, J.R. Pilcher, V.C. LaMarche Jr. Cambridge University Press, Cambridge, U.K. pp. 38-45.

Guiot, J., Berger, A.L. Munaut, A.V., and Till, C. 1982b. Some new mathematical procedures in dendroclimatology with examples for Switzerland and Morocco. Tree-Ring Bull. 42: 33-48.

Harrison, S.P., Prentice, I.C., and Guiot, J. 1993. Climatic controls of Holocene lake-level changes in Europe. Clim. Dyn. 8: 189-200.

Hastie, T., and Loader, C. 1993. Local regression: automatical kernel carpentry (with discussion). Stat. Sci. 8: 120-143.

Heshmaty, B., and Kandel, A. 1985. Fuzzy linear regression and its applications to forecasting in uncertain environment. Fuzzy Sets Syst. 15: 159-191.

Jarvis, P.G., and MacNaughton, K.G. 1986: Stomatal control of transpiration: scaling up from leaf to region. Adv. Ecol. Res. No. 15. pp. 1-49.

Kaufmann, A., and Gupta, M.M. 1991. Introduction to fuzzy arithmetic: theory and applications. Van Nostrand Reinhold, New York.

Lebourgeois, F. 1995. Étude dendroécologique et écophysiologique du Pin laricio de Corse (Pinus nigra A. ssp. laricio) en région pays de Loire. Ph.D. thesis, Université de Paris-Sud, Orsay, Paris, France.

Neter, J., Wasserman, W., and Kutner, M.H. 1989. Applied linear regression models. 2nd ed. Irwin, Homewood, Ill.

Prentice, I.C., Cramer, W., Harrison, S.P., Leemans, R., and Monserud, R.A. 1992. A global biome model based on plant physiology and dominance, soil properties and climate. J. Biogeogr. 19: 117-134.

Prentice, I.C., Sykes, M.T., and Cramer, W. 1993. A simulation model for the transient effects of climate change on forest landscapes. Ecol. Modell. 65: 51-71.

Redden, D.T., and Woodall, H. 1996. Further examination of fuzzy linear regression. Fuzzy Sets Syst. 79: 203-211.

Schweingruber, F.H., Kairiukstis, L., and Shiyatov, S. 1990. Sample selection. In Methods of dendrochronology. Edited by E.R Cook and L.A Kairiukstis. Kluwer Academic Publishers and IIASA, Dordrecht, the Netherlands. pp. 23-96.

Shashkin, A.V., and Fritts, H.C. 1995. A model that simulates cambial activity and ring structure in conifers. In Tree rings, from the past to the future. Edited by S. Ohta and M.K. Hughes. Forestry and Forest Products Research Institute, Tsukuba, Japan. pp. 24-30.

Tanaka, H., Uejima, S., and Asai, K. 1982. Linear regression analysis with fuzzy model. IEEE Trans. Syst. Man Cybern. 12: 903-907.

Viertl, R. 1997. Non-precise information in Bayesian inference. In Statistical and Bayesian methods in hydrological sciences. Edited by E. Parent and B. Bobie. UNESCO Press, Paris. pp. 465-478.

Zadeh, L.A. 1965. Fuzzy sets. Inf. Control, 8: 338-353.

Zadeh, L.A. 1973. Outline of a new approach to the analysis of complex systems and decision processes. IEEE Trans. Syst. Man. Cybern. 3: 28-44. 